\title{
FEMINISMO DE ESTADO PÓS 2016: O CONTEXTO IMPORTA?
}

\section{Milena Cristina Belançon ${ }^{1}$}

RESUMO: A ocupação de cargos na burocracia estatal foi um repertório de interação ativado por diversos movimentos sociais brasileiros, principalmente a partir da redemocratização, para que políticas públicas fossem colocadas em pauta no Estado. O movimento feminista foi um grande entusiasta desse repertório, logrando resultados bastante interessantes para se pensar a relação entre movimento social e Estado, e constitui o objeto deste trabalho. A partir de um levantamento histórico acerca da institucionalização do movimento feminista, recuperamos alguns instrumentos analíticos sugeridos para se abordar o contexto político. Desse modo, buscamos traçar uma sistematização de contribuições recentes, que foram demandadas pela realidade brasileira para medir o que não é apenas conjuntural e perene, mas também os resultados que perduram ao longo do tempo.

Palavras-chave: Movimento Feminista. Estado. Políticas Públicas.

\section{INTRODUÇÃO}

O movimento feminista brasileiro contemporâneo, que tem seu marco de efervescência na ditadura militar (1964 - 1985), lutou bravamente na resistência ao Estado opressor daquele momento. Com a abertura política e a experiência adquirida no período, o movimento levantou a bandeira das questões de gênero enquanto fundamentais para a democracia, e dessa forma, evidenciou-se a necessidade de politizar a vida privada.

Constituída de grande complexidade, a aproximação do movimento feminista ao Estado se deu de diversas formas, por meio da parceria entre ONGs e poder público, participação ativista em Conselhos Gestores e Conferências de políticas públicas, e também via ocupação de cargos na burocracia estatal, em um fenômeno que a bibliografia chamou de Feminismo de Estado.

O conceito de Feminismo de Estado (State Feminism), assim como diversos conceitos voltados a entender a realidade, é complexo e possui diversas interpretações. Segundo Paradis (2013), o conceito trata de um desenvolvimento teórico feminista a respeito do Estado, basicamente orientado pelas "ações dos mecanismos institucionais de mulheres para incluir as demandas e as agentes do movimento de mulheres no interior do Estado, de modo a produzir resultados feministas nos processos políticos e impacto social ou ambos" (Mcbride; Mazur, 2008a, p. 255 apud Paradis, 2013).

1 Mestranda no Programa de Pós-Graduação em Ciências Sociais da Universidade Estadual de Maringá. Pesquisadora do Núcleo de Pesquisas em Participação Política (NUPPOL/UEM).milenabelancon@gmail.com. 
Assumimos aqui a referência àquela parte da bibliografia que considera o Feminismo de Estado enquanto uma mudança na visão do último, operando em ressignificar as relações Estadosociedade (Lovenduski, 2005). Desse modo, vemos o Feminismo de Estado enquanto um conjunto de práticas, mecanismos, ações, que operam no sentido de mover as estruturas do Estado, atuando por dentro dele visando o avanço de pautas de direitos das mulheres. Nesse sentido, segundo Clarisse Paradis (2013), podemos pensar o conceito enquanto um "tipo ideal", sendo que quanto mais dimensões em uma situação estatal, mais esse Estado se aproximaria do feminismo estatal.

É sabido que diversos movimentos sociais se colocaram no caminho da institucionalização via ocupação de cargos na burocracia, que a bibliografia chamou de ativismo institucional (Cayres, 2015; Feltran, 2006). Porém, a nossa opção por estudar o movimento feminista se deu por notar a grande repercussão que os estudos da área forneceram para a literatura de movimentos sociais, adquirindo assim notável projeção nos estudos. Além disso, o movimento feminista guarda particularidades interessantes para análise, como o histórico de sua relação com o Estado, e também a constituição de redes que articulam diversos repertórios com um mesmo propósito. Por exemplo, o movimento de rua, a presença de ativistas nos Conselhos Gestores, a presença de um ativista em cargo comissionado relativo à pasta, etc. Além disso, outra particularidade desse movimento está na reação, que tal institucionalização e avanços em questão de políticas públicas, fizeram repercutir nos setores conservadores da sociedade brasileira.

Traçando como objetivo apontar referenciais analíticos que nos fornecem instrumentos e sugestões para incluir a ideia de contexto político no que se refere às possibilidades dos movimentos sociais influenciarem políticas públicas, este trabalho está dividido em duas partes além dessa introdução e notas conclusivas. A princípio, descrevo o histórico da atuação feminista no Estado, assim como alguns conceitos que acompanharam esse processo, em seguida, traçamos relações entre conceitos propostos pela bibliografia de movimentos sociais e a bibliografia feminista, com o intuito de indicar possíveis diálogos complementares para a observação das relações entre Movimento Feminista e Estado no Brasil, enfatizando a questão da importância do contexto político nas possibilidades dessa relação.

\section{FEMINISMO E ESTADO}

\subsection{MUDANÇAS CONTEXTUAIS E REPERTÓRIOS DE INTERAÇÃO}

Para compreender melhor a relação entre Estado e Movimento Feminista devemos recorrer a alguns conceitos. As mudanças ocorridas na sociedade e na política fazem com que os conceitos utilizados pela bibliografia sejam ampliados e repensados, por exemplo, a Teoria dos Processos Políticos (TPP), que tem como referências Charles Tilly (2013) e Sidney Tarrow (2009), consagrada nos estudos de movimentos sociais, analisava estes em relação conflituosa com o Estado, operando na ótica do confronto com as instâncias de poder legal. Porém, a expansão da agenda de pesquisa notou que a relação entre os movimentos sociais e o Estado passou por mudanças, incluindo interações cooperativas e colaborativas entre estes, fazendo com que a bibliografia buscasse novos conceitos que fossem capazes de suscitar análises mais adequadas.

Outra característica levada em conta para adequação dos conceitos é o recorte geográfico, que influencia também o contexto político e social. Desse modo, diversas autoras e autores latino-americanos também empenharam-se em construir teorias que possibilitassem uma melhor compreensão dos fenômenos de nossa realidade. 
Um exemplo está em Abers, Serafim e Tatagiba (2014), que buscando ampliar o conceito de repertório de ação, proposto por Sidney Tarrow (2009), empregaram o conceito de repertórios de interação, chamando a atenção para os repertórios que não são necessariamente de confronto com o Estado, mas muitas vezes de cooperação e interação. Essa proposição das autoras se dá como forma de complementar o conceito de Tarrow, que buscava analisar os repertórios de ação sempre em confronto com o Estado, ou seja, o objeto desse conceito seriam as práticas e ações organizadas pelo movimento de modo conflitivo com o Estado, na luta contra este. Desse modo, a teoria do autor deixa escapar outros tipos de repertórios, que não tinham como fim o embate com o Estado, mas muitas vezes uma luta que não envolvia o Estado ou também aquelas em que não visavam o conflito, mas outras formas de interação.

As autoras avaliam ainda que existem diferentes tipos de interação, em seu trabalho elencam quatro rotinas comuns de tal interação, são elas: Protestos e Ação Direta, Participação Institucionalizada, Política de Proximidade e Ocupação de Cargos na burocracia (Abers, Serafim, \& Tatagiba, 2014). E estas são explicadas em grande parte pela especificidade encontrada nas singularidades históricas que marcam a relação dos movimentos sociais com as diferentes áreas da política pública. Desse modo, para compreender a relação entre o movimento social e o Estado é preciso observar os padrões históricos dessa relação em cada movimento e cada área de política em particular.

No Brasil, os repertórios de interação tiveram grande destaque a partir do período de redemocratização. Isso porque se constituía como pauta de muitos movimentos sociais a abertura para uma democracia participativa, em contraste com a repressão e autoritarismo vividos no período. Essa aproximação entre movimentos feministas e Estado adquiriu materialidade aos poucos, por meio da criação nas esferas nacional, estaduais e municipais, de Conselhos Gestores de Políticas para Mulheres (CPMs), Conferências de Políticas para Mulheres, elaboração dos Planos de Políticas para Mulheres, criação de secretarias e órgãos voltados para a promoção de igualdade entre gêneros, entre outras medidas que indicaram a possibilidade de institucionalização de demandas que partiram do movimento feminista (Rangel, 2013).

Segundo Sonia Alvarez (2000), na América Latina de modo geral, as décadas de 1960 e 1970 foram marcadas pela luta contra o capitalismo implantado pelos militares, onde a maioria dos movimentos deu as costas para o Estado e evitou a arena política convencional (p. 387), até porque essa era a única alternativa no momento, uma vez que o período militar foi de forte repressão e tortura às organizações de movimentos sociais. A autora aponta que o movimento se constituiu em oposição ao autoritarismo que estava colocado, mas também em oposição muitas vezes às formas tradicionais de organização dentro do campo de esquerda, rigidamente formalizadas, provocando o despertar para a importância da luta na vida cotidiana, e aos problemas do cotidiano das mulheres, como questões sobre papéis de gênero e divisão sexual do trabalho.

Essa atuação dentro das organizações anti-ditadura estendeu os horizontes das ativistas, fazendo-as aprender outras formas de fazer política, que extrapolavam os canais partidários. Portanto, com o fim da ditadura, em meados da década de 80, mulheres já estavam exercendo ação profissional em militância, constituindo ONGs e buscando o avanço das pautas de gênero através de diferentes meios. Desse modo, os avanços nas pautas feministas puderam acontecer, ainda que timidamente, no pós-ditadura mesmo com a pequena presença feminina nas instâncias tradicionais de representação. A atuação extraparlamentar, por meio dos movimentos de mulheres, as redes feministas, ONGs, Conselhos gestores, conferências temáticas, etc., foi, portanto, uma alternativa encontrada para que as pautas chegassem à agenda pública. 
Ainda no processo de abertura política, em 1985, foi criado o Conselho Nacional dos Direitos da Mulher (CNDM), um desdobramento das lutas pela saúde da mulher, que junto aos movimentos de mulheres e feministas, obtiveram atuação marcante ao dar visibilidade a um conjunto de reivindicações relativas ao processo de exclusão das mulheres (Abers \& Tatagiba, 2015).

O CNDM liderou campanhas como "Constituinte sem mulher fica pela metade", que marcou o período de redemocratização, e culminou na apresentação da Carta das Mulheres Brasileiras aos Constituintes $^{2}$, que indicava de forma completa e abrangente as demandas das mulheres para o documento. Segundo Céli Pinto (2003), a bancada feminina, mesmo com sua heterogeneidade, apresentou 30 emendas sobre os direitos das mulheres, englobando praticamente todas as reivindicações do movimento feminista.

Muitas dessas pautas foram acolhidas na Constituição de 1988 (Blay \& Avelar, 2017; Pinto, 2003) e operaram como instrumentos de institucionalização das políticas para mulheres. Porém, de partida já é possível notar a seletividade do Estado e a dificuldade de inclusão de demandas feministas neste, com o fato de que a pauta dos direitos sexuais e reprodutivos foi um dos principais itens não acatados na Constituição, o que a bibliografia trata exaustivamente como a grande lacuna dessa conquista.

O contexto de abertura política trouxe ainda outras tensões ao movimento feminista. Segundo Machado (2016), "àquele momento, a pressão e o contexto político eram favoráveis aos avanços dos direitos das mulheres, como se incluídos estivessem na conquista da democracia e do 'progresso social', muito embora resistências fizessem lugar" (n.p). Nesse sentido, Alvarez (2000) aponta que os anos 90 configuraram novas tendências aos movimentos feministas latino-americanos, que foram constituídas pela (1) proliferação de espaços e lugares em que feministas atuam, (2) absorção de discursos e agendas feministas por instituições dominantes (incluindo o Estado e órgãos internacionais), (3) profissionalização e especialização de setores do movimento feminista ("onguização"), (4) articulação e formação de redes e (5) transnacionalização. Tais tendências demonstram um descentramento saudável, caracterizado por ela como campo de ação expansivo, policêntrico e heterogêneo, mas, por outro lado, desencadearam também contradições profundas, gerando novos conflitos relacionados aos lugares, alvos e objetivos apropriados da política feminista.

Essas contradições foram tratadas exaustivamente pela bibliografia. Lobo (1991, p. 225 apud Santos, 2006, p. 418), por exemplo, aponta que o processo de criação dos Conselhos de mulheres gerou duas visões diferentes sobre o movimento: de um lado, aquela que defende que as mulheres devem ocupar novos espaços governamentais, e de outro, aquela que afirma que o espaço das feministas deveria ser exclusivamente a militância fora da estrutura estatal.

Essa disputa também é tematizada por Sonia Alvarez (2000; 2014), que recorda o fato deste ser um campo em constante luta política por hegemonia, onde há, portanto, divergências entre as feministas "autônomas" e as feministas "institucionais", sendo as primeiras àquelas que negam qualquer tipo de institucionalização do movimento, e as últimas àquelas que são abertas ao relacionamento com o Estado com o intuito de avançar pautas por esse meio, ainda que não descartem também outros tipos de repertório de ação.

A aproximação com o Estado, portanto, motivou discussões acerca da autonomia e cooptação do movimento, nesse sentido Patrícia Rangel (2013) afirma que

2 Disponível em http://www2.camara.leg.br/atividade-legislativa/legislacao/Constituicoes_Brasileiras/constituicao-cidada/constituintes/a-constituinte-e-as-mulheres/Constituinte \%201987-1988-Carta\%20das\%20Mulheres\%20aos\%20Constituintes.pdf 
[...] a ideia de autonomia precisa ser repensada no contexto da democratização, uma vez que, quando militantes assumem cargos no governo ou obtêm sucesso em influenciá-lo de fato, a distinção entre Estado e sociedade civil deixa de ser tão nítida. Assim, é possível que atores estatais contribuam para que grupos ou movimentos ganhem capacidades políticas (Rangel, 2013, p.4).

Desse modo, apesar dos limites e da falta de consenso sobre a aproximação do movimento com o Estado, a bibliografia aponta esse momento de forte ativismo como semente que se transformou num amplo mosaico participativo/representativo (Avelar e Rangel, 2017, p. 273), referindo-se à criação de instâncias participativas que se deu no decorrer na redemocratização. Segundo Alvarez (2000), a absorção de pautas feministas pelo Estado e pela ONU, ainda que de forma deficitária se deve "à eficácia de incansáveis intervenções daquele grupo crescente de feministas que 'ocupou', senão 'conquistou', espaços em uma grande quantidade de públicos dominados pelos homens em anos recentes” (p. 399) podemos considerar como um desses espaços, o próprio Estado.

Ampliando esse debate, Abers e Bülow (2011) apontam a importância da construção de redes que integram diferentes repertórios com um mesmo fim, fazer avançar uma pauta e/ou política pública. Essas redes seriam responsáveis por cruzar fronteiras entre Estado e sociedade. Desse modo, as autoras afirmam "que a literatura que discute movimentos sociais a partir da ótica de redes possibilita compreender ativistas dentro do Estado não apenas como interlocutores amigos, e sim como parte da nossa unidade de análise” (Abers e Büllow, 2011, p. 55).

\section{CONTEXTO POLÍTICO E POLÍTICAS PÚBLICAS FEMINISTAS}

A institucionalização de políticas para mulheres no Brasil tomou força a partir dos anos 2000, como podemos conferir no quadro 1. Além disso, podemos notar a atuação de uma série de dispositivos institucionais, com o intuito de fortalecer a política. Há ainda o processo de criação de uma rede, onde os Conselhos Gestores em parceria com os Organismo de Política para Mulheres foram responsáveis pela organização das Conferências (onde as nacionais foram precedidas por estaduais e municipais). E ainda, das Conferências Nacionais saíam os Planos Nacionais, que designavam metas, condutas, estratégias para o fortalecimento das Políticas para Mulheres. Desse modo, o ideal dessa rede envolvia todos os instrumentos de políticas públicas em uma construção participativa.

Quadro 1 - Série histórica da institucionalização das demandas para mulheres

\begin{tabular}{|c|c|}
\hline Ano & Ação \\
\hline 1983 & Criação do Conselho Estadual da Condição Feminina de São Paulo \\
\hline 1985 & Criação do Conselho Nacional de Defesa da Mulher (CNDM) \\
\hline 2002 & Criação da Secretaria de Estado dos Direitos da Mulher ${ }^{3}$ \\
\hline 2003 & Criação da Secretaria Nacional de Políticas para Mulheres (SPM) \\
\hline 2004 & 1 Conferência de Políticas para Mulheres (CNPM) $^{\text {a }}$ \\
\hline 2005 a 2007 & Vigência do I PNPM (Plano Nacional de Política para Mulheres) \\
\hline
\end{tabular}




\begin{tabular}{|c|c|}
\hline 2006 & Criação da Lei $n^{\circ}$ 11340 (Lei Maria da Penha) \\
\hline 2007 & $2^{\text {a } \text { CNPM }}$ \\
\hline 2008 a 2011 & Vigência do II PNPM \\
\hline 2011 & $3^{\text {a } \text { CNPM }}$ \\
\hline 2013 a 2015 & Vigência do III PNPM \\
\hline 2016 & $4^{\text {a CNPM }}$ \\
\hline
\end{tabular}

Fonte: Adaptado de Almeida, Belançon e Chaves (2019).

É nítido que grande parte das ações que se referem ao Feminismo de Estado foram consolidadas a partir da chegada do Partido dos Trabalhadores (PT) ao governo federal, que se deu em 2003 com a eleição de Luiz Inácio Lula da Silva. A bibliografia aponta que o boom do ativismo institucional nesse período não se bastou ao movimento feminista, sendo um marco para a grande maioria dos movimentos sociais, que devido ao novo contexto que se desenhara puderam contar com mais repertórios de interação com o Estado. Isso porque no corpo do PT havia muitos militantes de diversos movimentos, que traziam consigo um ideal participativo da gestão das políticas públicas, como aponta a bibliografia (Abers et al., 2014; Cayres, 2015; Feltran, 2006).

Também, nesse sentido, Simone Bohn (2010) afirma que governos de partidos políticos ou coalizões progressistas são considerados mais conducentes tanto à implantação de uma Agência de Políticas Públicas para Mulheres (APM), quanto ao incremento de sua força institucional no interior da burocracia estatal. Isso porque partidos progressistas usualmente incorporam em sua plataforma programática questões de equidade de gênero, o que os aproxima dos objetivos dos movimentos feministas e facilita o processo de legitimação de uma agência de políticas públicas para mulheres.

Desse modo, podemos notar que, no Brasil, o período dos governos petistas (2003-2016) atuou como um marco histórico para o Feminismo de Estado, o que pode ser explicado por vários fatores, entre eles, o PT ser um partido alinhado à esquerda no espectro político ideológico, e conter muitas feministas em seu corpo, inclusive mulheres que há pouco tempo haviam estado na luta contra a ditadura e passaram cada vez mais a entender que não existe democracia sem a participação das mulheres.

Em pesquisa sobre a expansão e efetividade dos Organismos e Conselhos Gestores de políticas para mulheres nos municípios brasileiros, Belançon, Almeida e Chaves (2018) apontam que a partir de 2003 o crescimento quantitativo dessas instâncias é notável, ainda que sua cobertura no território nacional permaneça muito baixa. E sugerem que a qualidade dos serviços oferecidos às mulheres em municípios que contam com essa rede de dispositivos é melhor.

Com isso, percebemos a necessidade em se investigar com mais profundidade qual é o impacto desse contexto político, e qual seria a maneira mais adequada de incluir a ideia de contexto político para compreender as possibilidades dos movimentos influenciarem nas políticas públicas.

\subsection{CATEGORIAS RELACIONAIS PARA ANALISAR POLITICAS PÚBLICAS E FEMINISMO DE ESTADO}

Ann Banaszak (2005, p. 154) sugeriu que se quisermos compreender as interações entre movimentos e Estado, precisamos de uma perspectiva teórica que incorpore uma compreensão tanto 
dos movimentos quanto do Estado como entidades diversas que podem ter múltiplos pontos de intersecção. Tal perspectiva deve reconhecer a intersecção entre Estado e movimentos e analisar seus efeitos no desenvolvimento e nas táticas do movimento, bem como seus resultados. Fazendo coro a essa perspectiva, Adrian Lavalle e colaboradores (2017)pontuam que "precisamos de categorias que permitam observar os Mss [movimentos sociais] em interação com as instituições do Estado e detectar as gradações de permanência e de influência dos atores sociais nos processos decisórios e seus efeitos." (Lavalle et al., 2017, p. 15)

Como o objeto deste trabalho são as políticas para as mulheres, partimos do exemplo da criação da Secretaria de Políticas para Mulheres (SPM), destacando primeiramente sua força institucional, uma vez que no governo do Presidente Lula, em 2003, esta adquiriu caráter ministerial, abrindo a demanda para que os estados e municípios criassem pastas específicas para tal política em suas gestões, como já apontado anteriormente.

Por ser a criação de um organismo próprio para esta área, uma demanda do movimento feminista, pode-se afirmar que a atuação das feministas no Estado - que a bibliografia chamou de femocratas - auxiliou o surgimento de órgãos específicos de políticas para mulheres, e por sua vez, a criação de órgãos específicos também aumentou a demanda por feministas no Estado, uma vez que muitas vezes eram procuradas mulheres dos movimentos sociais para ocuparem tais cargos. Esse legado da SPM demonstra a criação de capacidades estatais que possibilitam a inserção de novas atrizes em tal realidade.

Segundo Gomide, Pereira, \& Machado (2018), as definições de capacidade estatal difundidas na literatura dizem respeito ao poder de produção de políticas públicas pelas burocracias do Estado. Neste trabalho, utilizamos o conceito de capacidades estatais para se referir aos "instrumentos" disponíveis para a construção de uma política. Esses instrumentos podem ser entendidos como recursos administrativos, humanos e orçamentários, ou seja, ministérios, gabinetes, corpos magistrados, meios de coerção, secretarias, câmaras, assembleias, etc. Tais capacidades podem facilitar ou dificultar as interações com atores civis, e tendem a aumentar ou bloquear suas chances de acesso ao Estado e à cristalização de suas demandas e interesses. É importante enfatizar que a construção destas capacidades é relacional, uma vez que

[...] a capacidade estatal tanto molda as chances e estratégias de acesso e sucesso de interesses e demandas das Organizações da Sociedade Civil (OSCs) e dos Movimentos Sociais (MSs), como é moldada e incrementada pela interação desses últimos atores com instituições e atores do Estado. (Lavalle et al., 2017)

Desse modo, podemos observar que a criação da SPM incrementou a relação do movimento social com o Estado, ao mesmo tempo que foi moldada a partir de tal relação.

Seguindo essa linha de raciocínio, podemos pensar também o conceito de "oportunidades políticas". De forma geral, o conceito segue tratando da relação entre movimento e Estado, enfocando em questões mais contextuais para se compreender o que o Estado oferece para o movimento social em se tratando de conveniências e cerceamentos. Isso foi o que Tarrow e colaboradores mostraram, ao indicar que as oportunidades políticas tratavam do quanto a configuração do sistema político pode incentivar ou restringir ações coletivas. Sidney Tarrow argumenta que o confronto político está relacionado a oportunidades de ação coletiva, para o autor, as oportunidades são responsáveis pela escolha de iniciar ou intensificar um confronto. Entre alguns momentos de oportunidades o autor destaca: quando há aberturas institucionais, divisões entre as elites, aliados 
disponíveis e quando diminui a capacidade de repressão do Estado. Estes fatores são combinados à percepção que a falta de ação pode ser mais custosa do que tomar uma atitude, levando assim a confrontos e insurgências (Tarrow, 2009, p. 99).

Porém, Banaszak (2005) aponta a possibilidade do caminho inverso, ou seja, o movimento social moldar as oportunidades políticas, demonstrando o poder de agência dos movimentos uma vez inseridos na burocracia. Nesse mesmo sentido, Carlos, Dowbor, \& Albuquerque (2017) reconhecem que as oportunidades políticas contextuais impactam na permeabilidade do Estado, ou seja, o quão poroso o Estado é aos movimentos sociais. Porém, destacam que "uma vez desencadeada a mobilização, as características amplas do sistema político deixam de descrever e explicar o desenrolar da ação coletiva, e o próprio movimento acaba produzindo novas oportunidades" (Carlos, Dowbor e Albuquerque, 2017, p. 370) ${ }^{4}$. Desse modo, fazemos coro ao posicionamento de Abers, Silva, \& Tatagiba (2018), que apontam o caráter relacional desse conceito, em oposição àqueles que tratavam o contexto como um cenário inerentemente externo aos movimentos.

Os autores partem de uma proposta onde argumentam que

$[\ldots]$ ao invés de se relacionarem com uma estrutura de oportunidades políticas externa, os movimentos sociais estão inseridos em estruturas relacionais constituídas por agenciamentos recíprocos de diversos atores, redes e instituições que nelas agem, incluindo os próprios movimentos (Abers et al., 2018, p. 25).

Nesse sentido, o conceito de estruturas relacionais enfatiza que o contexto é constituído por relações entre atores que, uma vez instituídas, estruturam ações futuras. Essas estruturas relacionais se expressam pelo regime e subsistemas, onde o regime seria o conjunto das instituições e ideias que regulam a luta pelo poder e seu exercício em uma sociedade, constituído pelos atores estatais e não estatais que têm acesso às discussões e decisões governamentais. Já os subsistemas seriam campos de atores e instituições que se especializam e direcionam seus esforços para algumas questões específicas em relação a uma política (Capella e Brasil, 2015, p. 58, apud Abers et al., 2018, p. 34).

Desse modo subsistemas aparecem como arenas de disputa, onde seu processo de mudança ocorre ao mesmo tempo por dentro deste e em função de mudanças externas na sociedade mais ampla (Sabatier e Jenkins-Smith, 1993, apud Abers et al., 2018, p. 35).

Mais uma vez o setor da política é importante para refletir sobre a relação Estado e sociedade, e mais precisamente agora, a estrutura relacional. Segundo os autores, a eleição de Lula representou uma mudança no regime, que ampliou o acesso ao governo por parte de movimentos mais próximos à coalizão governante. O que é aconteceu no caso do movimento feminista, que pode contar com diversas feministas - ou mulheres simpáticas ao feminismo, ainda que não declaradas - ocupando o cargo de Ministra da SPM e também outras funções de suma importância dentro da pasta.

Em relação aos subsistemas, são representados pelo conjunto de políticas de cada setor e segundo os autores, com sua consolidação, passam a ser, muitas vezes, independentes do apoio político da coalizão do governo. Exemplos são dados a partir do golpe de 2016, onde houve uma mudança do regime e alguns subsistemas consolidados se mostraram enquanto resistência por conta da absorção de ideias dos movimentos sociais, já outros, foram desmantelados por manter relação muito forte com o regime. 
O caso das políticas para mulheres, notamos que ao mesmo tempo que esta consolidou-se através de Organismos, leis, Conselhos Gestores, etc., há uma perseguição muito grande ao seu caráter feminista, tornando-se um caso bastante interessante para nossa análise.

\subsection{SUBSISTEMA DAS POLITICAS PARA MULHERES}

Para expandir um pouco mais a análise sobre as políticas para mulheres, podemos pensar sobre o conceito de "encaixe institucional", de Lavallee colaboradores (2017). O conceito trata dos espaços e entradas cavados por atores sociais no Estado, tornando-o poroso a seus interesses e valores, constituindo assim acesso mais solidificado ao Estado e aos processos decisórios, com atuação prolongada no tempo.

Dessa forma, podemos analisar a SPM como um "encaixe", já que, segundo eles encaixes "são sedimentações institucionais de processos de interação socioestatal que ganham vida própria" (Lavalle et al., 2017, p. 19).

Segundo os autores, a construção desses encaixes pode:

[...] (a) fortalecer as capacidades sociais através da complexificação organizacional das OSCs e MSs (mediante a gestão de programas e projetos governamentais, e a ocupação de cargos por militantes, por exemplo); (b) criar ou ampliar as capacidades estatais (mediante inovação ou experimentação sociais em instrumentos de políticas, órgãos e burocracias); (c) constituir as condições para a formação de redes de recrutamento e redes de apoiadores, de articulações e coalizões de defesa de causas, e até mesmo para a emergência de novas organizações que funcionam com articuladoras de redes (encontros, fóruns, comissões, conferências, conselhos e grupos de trabalho) (Lavalle et al., 2017, p. 25-26).

Levando em conta as proposições dos autores, ao observar os resultados da interação feminista com o Estado, podemos aferir que por meio da SPM fortaleceram-se as capacidades sociais, uma vez que houve aproximação entre sociedade e movimentos sociais das políticas públicas para mulheres. Houve também a criação e ampliação das capacidades estatais e constituição de redes, que incluíam diversos movimentos sociais, órgãos governamentais, ONGs feministas e a sociedade civil. Exemplos disso são, a realização das Conferências de Políticas para Mulheres, a ênfase dada à transversalidade na implementação de políticas públicas e a própria atuação das feministas no Estado.

Os autores chamam a atenção para a constatação de que o encaixe é ao mesmo tempo "o resultado de processos de interação e uma criatura ou artefato institucional que adquire densidade própria” (Lavalle et al., 2017, p.20). Desse modo, uma vez criado o encaixe, ele se torna independente de seus criadores.

Ou seja, trazendo para o contexto deste trabalho, a estrutura de Organismos de Políticas para Mulheres no Brasil foi criada em grande parte por influência e pressão dos movimentos feministas, porém, desde o início de 2019 está ocupada por forças políticas que não só não respondem mais aos anseios e princípios do movimento, como são antagônicas a este. Isso é demonstrado pelo fato de que a partir mudança de conjuntura política a pasta de políticas para mulheres perdeu seu caráter ministerial, sua exclusividade e também o caráter combativo e feminista que possuía, sendo 
ocupado por mulheres bastante contrárias às pautas feministas 5 .

Para além dos percalços dentro do próprio movimento feminista em busca das melhores formas de ação coletiva, notamos grandes reações à construção desse encaixe na estrutura estatal brasileira. No congresso, por exemplo, foi apelidada de "BBB - Bala, boi e bíblia" a bancada que a princípio representava um dos maiores obstáculos às pautas feministas e das minorias de forma geral $^{6}$, ainda durante os governos petistas. Este é um dos exemplos que podemos citar de uma grande reação conservadora que atingiu não só a esfera institucional, mas a sociedade de modo geral. Entre essas reações, cada vez mais escancaradas, podemos citar o projeto de lei no ${ }^{\circ}$ 5069/2013, que propõe alterações no código penal para complicar ainda mais o atendimento ao aborto, e também o Projeto Escola Sem Partido. Sobre este último, Carvalho, Polizel e Maio (2016) destacam que,

na prática, propõe uma educação descolada de criticidade e que sustenta o status quo. Questões contundentes como gênero, política, etnia, violência, sistemas econômicos, exploração de classes e subalternização de pessoas deveriam ser proibidos em sala de aula. A escola se encarregaria apenas da formação técnica e conteudista dos estudantes num processo de repetição sistemática dos conhecimentos relativos a cada área ou disciplina. (Carvalho, Polizel e Maio, 2016, p. 202).

Com todas essas ameaças aos direitos das mulheres, observamos o quanto a institucionalização do feminismo foi, e ainda é, um ponto crucial no contexto político, Abers e Tatagiba (2015) apontaram o quanto as relações foram tensas no Governo Dilma (PT), que segundo elas, foi um "período no qual grupos conservadores cada vez mais poderosos associados com o lobby religioso anti-aborto, colocaram grandes constrangimentos ao que as feministas podiam fazer" (Abers e Tatagiba, 2015, p. 76, tradução livre). Compondo a crise política vivida ao final do Governo Dilma, em 2016 uma reforma ministerial acabou diluindo a SPM junto a outras pastas 7 .

Pouco depois, houve a consumação do Golpe de 2016, que expôs o peso desigual de mulheres e homens em cargos eletivos, por conter elementos carregados de misoginia. A simbologia de uma mulher sendo deposta e sucedida por um homem que nomeou ministérios compostos exclusivamente por homens brancos é um dos componentes que elucida esse peso. Junto disso, a SPM não voltou a ser Ministério, passando por diversas pastas e diminuindo seu grau na hierarquia de poder, ${ }^{8}$ isso fez com que muitas outras secretarias de mulheres estaduais e municipais também fossem dissolvidas, por falta de recursos e também de vontade política.

5 "Decreto transfere secretaria de política para mulheres para o ministério dos direitos humanos" http://www.mdh.gov.br/ todas-as-noticias/2018/junho/decreto-transfere-secretaria-de-politica-para-mulheres-para-o-ministerio-dos-direitos-humanos "Feministas criticam escolha de socióloga contra aborto para secretaria de política para mulheres" https://revistamarieclaire. globo.com/Noticias/noticia/2016/06/feministas-criticam-escolha-de-sociologa-contra-aborto-para-secretaria-de-politica-para-mulheres.html

6 https://www.cartacapital.com.br/revista/844/bbb-no-congresso-1092.html

7 "Dilma anuncia redução de 39 para 31 pastas na reforma ministerial” http://g1.globo.com/politica/noticia/2015/10/ dilma-anuncia-reducao-de-39-para-31-pastas-na-reforma-ministerial.html

8 O Decreto n ${ }^{\circ}$ 9.417, de 20 de junho de 2018, transferiu a Secretaria Nacional de Políticas para Mulheres para a estrutura organizacional do Ministério dos Direitos Humanos, que a partir 2019 passou a chamar-se Ministério da Mulher, da Família e dos Direitos Humanos (MMFDH). 
Em consonância com a ofensiva conservadora que vivemos, a eleição presidencial de 2018 foi extremamente marcada por caloroso debate acerca de pautas morais, findando pela eleição de Jair Bolsonaro (PSL), candidato declaradamente contra ativismos, sendo um de seus principais alvos o movimento feminista. Principalmente após manifestações massivas contra sua candidatura, encampadas por mulheres de todo o Brasil nos atos "\#eleNão".

Esse movimento ofensivo se dá, segundo Flávia Biroli (2019), porque o feminismo é potência e alvo. Segundo a autora essa seria

uma reação que se estabelece duplamente. Trata-se de reação à atuação dos movimentos feministas no âmbito do Estado. Mas se trata, também de reação a mudanças sociais, ao cotidiano das relações de gênero, em que a vivência da sexualidade e as configurações do feminino e do masculino se alteraram. Daí parte dessa reação estar voltada diretamente para o debate nas escolas, procurando restringir não apenas a perspectiva de gênero nas políticas públicas e nos conteúdos escolares, mas cercear o debate (Biroli, 2019, p. 114).

Desse modo, Débora Gonzalez (2018, p. 4), levando em conta a influência do contexto político e disputas internas ao funcionamento dos organismos de políticas para mulheres (OPMs), sugere analisar estes de uma "perspectiva relacional e conjuntural, não como parte de uma maquinaria burocrático-estatal homogênea e fixa, mas antes em seu caráter dinâmico e complexo, como arenas de/em disputas".

Arenas de disputa por serem espaços para conflitos e negociações constantes em torno de significados, orientações, orçamentos, prioridades, formas de gestão, etc., e todos os demais aspectos que envolvem construir e fazer políticas públicas para as mulheres, para além da dicotomia Estado/sociedade. Arenas em disputa, pois suas possibilidades de ação, poder de decisão e sua própria existência não estão dados tão somente com a sua criação enquanto organismo estatal; dependem primordialmente de correlações de forças, vontade política, recursos, pressão social e negociações constantes (Gonzalez, 2018, p.4).

Desse modo, após as eleições de 2018, passamos pela acentuação da disputa em tais arenas, uma vez que a mudança do Governo Federal trouxe para a pasta das mulheres uma Pastora com posicionamentos bastante conservadores e declaradamente anti-feminista. O próprio nome da pasta já sugere a mudança da perspectiva, antes "Secretaria de Políticas para Mulheres", em 2019 temos o "Ministério de Estado da Mulher, Família e Direitos Humanos". Ao chamar a "Família" para compor o título do ministério, podemos notar que a intenção é de reação às mudanças e avanços da sociedade brasileira, associar as mulheres ao lar, à família e aos cuidados, como já foi exaustivamente discutido é uma forma de recolher as mulheres ao âmbito privado mais uma vez.

A Ministra Damares, responsável pela pasta, desde o início de sua gestão tem dado declarações polêmicas e extremamente contrárias à agenda feminista, além disso a promoção de eventos e falas que buscam "revelar" o feminismo ${ }^{10}$, indicam o quanto esse subsistema, para usar o conceito de Abers, Silva e Tatagiba (2018), se configura como a arena de/em disputa.

9 “\#EleNão: A manifestação histórica liderada por mulheres no Brasil vista por quatro ângulos” < https://www.bbc. com/portuguese/brasil-45700013>

10 "Ministério da Mulher organiza evento com palestra sobre as armadilhas do feminismo" https://oglobo.globo.com/ sociedade/ministerio-da-mulher-organiza-evento-com-palestra-sobre-as-armadilhas-do-feminismo-23552270. 


\section{CONCLUSÕES}

O artigo foi escrito orientado pela questão "Como incluir a ideia de contexto político para compreender as possibilidades dos movimentos influenciarem as políticas públicas?”, utilizando como objeto de análise o movimento feminista. O trabalho foi direcionado para pensar o repertório de ocupação de cargos na burocracia estatal e para tanto, traçamos um histórico acerca da institucionalização do movimento feminista e recuperamos alguns instrumentos analíticos sugeridos para se abordar o contexto político.

Desse modo, a sistematização de contribuições recentes nos trouxe a reflexão de como medir o que não é apenas conjuntural e perene, mas também os resultados que perduram ao longo do tempo. Com isso, suscitamos as disputas em torno do Estado, há muito indicado pelas feministas como espaço de difícil acesso e de grandes restrições para as mulheres. Tal inflexão foi impulsionada principalmente pela mudança de contexto recente no Brasil, que colocou as questões de gênero no centro do debate e mexeu com as "estruturas" que estavam sendo construídas pelas feministas nas últimas décadas.

Tendo em vista a breve história da SPM enquanto órgão combativo, podemos observar que este constituiu-se enquanto um importante espaço de atuação de feministas e de avanço de pautas na agenda pública. Porém, percebemos que os pequenos passos que foram dados pelas feministas foram sentidos com muito peso por setores conservadores e moralistas. As pautas de direitos reprodutivos e sexuais, barradas na Constituição de 1988, conforme apontamos no texto, não só continuaram silenciadas pelo Estado, como atualmente, estão ainda mais cerceadas junto a outras pautas que pareciam já admitidas.

Principalmente a partir das eleições de 2018, a mudança de contexto recente demonstra que a estrutura relacional posta ao movimento feminista enfrenta ainda mais esse obstáculo, de ser perseguido por uma pauta "moral", mesmo sendo um subsistema aparentemente consolidado, notamos que ainda guardava uma relação muito forte com o regime.

Pleiteamos, com esse trabalho, superar ideias duais e oposicionistas sobre atuação no Estado e sobre o contexto político, construindo um diálogo entre conceitos muito caros aos movimentos sociais como oportunidades políticas, capacidades estatais, permeabilidade do Estado, estruturas relacionais, encaixes institucionais, etc. Com esse primeiro esforço, percebemos que muitos desses conceitos, apesar de terem raízes distintas, são convergentes como instrumentos de análise para o objeto proposto. Ressaltamos aqui que estas digressões carecem de maiores explorações, a fim de compreender o que cada conceito oferece para acrescentar nas análises de contexto político e políticas públicas.

Desse modo, apontamos que as relações entre Estado e Movimento Feminista ainda suscitam muitas reflexões para os estudos dos movimentos sociais. O subsistema (que pode ser visto também como um encaixe institucional) que se constituiu no Estado foi parcialmente desintegrado ou, teve seu caráter transformado. Isso porque a mudança do regime e das oportunidades políticas possivelmente influenciou de forma bastante abrupta a estrutura relacional. Porém, reconhecemos que do que foi criado pelas feministas que atuaram no Estado, nem tudo pode ser desmontado, pois além de ações institucionais, as femocratas operaram também enquanto agentes de mudanças culturais e fazem parte de uma lógica maior que abriga outros repertórios de ação e interação que não serão facilmente abolidos.

\section{REFERÊNCIAS}

ABERS, Rebecca; BÜLOW, Marisa Von. Movimentos sociais na teoria e na prática: como estudar o ativismo através da fronteira entre estado e sociedade? Sociologias. Porto Alegre: URGS, v. 13, n. 28, p. 52-84, 2011. 
ABERS, Rebecca; SILVA, Marcelo Kunrath; TATAGIBA, Luciana. Movimentos Sociais e Políticas Públicas: repensando atores e oportunidades políticas. Lua Nova: Revista de Cultura e Política. São Paulo: CEDEC, n. 105, p. 15-46, 2018.

ABERS, Rebecca; SERAFIM, Lizandra; TATAGIBA, Luciana. Repertórios de interação estado-sociedade em um estado heterogêneo: a experiência na Era Lula. Dados. Rio de Janeiro: UERJ, v. 57, n. 2, p. 325-357, 2014.

ABERS, Rebecca; TATAGIBA, Luciana. Institutional Activism: Mobilizing for Women's Health From Inside the Brazilian Bureaucracy. In: ROSSI, Federico M.; VON BÜLOW, Marisa (Orgs.). Social movement dynamics: new perspectives on theory and research from Latin America. Social movements, protest, and contention. New York: Farnham, Surrey, UK ; Burlington, VT, 2015. p. 73-101.

ALMEIDA, Carla; BELANÇON, Milena; CHAVES, Karen. Institucionalização de Demandas Feministas no Brasil: uma Análise dos Organismos, Conselhos e Serviços Especializados para Mulheres nos Municípios. Mediações. Londrina: UEL, v. 24, n. 3, p. 184-199, 2019.

ALVAREZ, Sonia. A 'globalização' dos feminismos Latino-Americanos: tendências dos anos 90 e desafios para o novo milênio. In: ALVAREZ, Sonia E.; DAGNINO, Evelina; ESCOBAR, Arturo (Orgs.). Cultura e política nos movimentos sociais latino-americanos: novas leituras. Belo Horizonte: Ed. UFMG, Univ. Federal de Minas Gerais, 2000.

ALVAREZ, Sonia E. Para além da sociedade civil: reflexões sobre o campo feminista. Cadernos Pagu. Campinas: UNICAMP, n. 43, p. 13-56, 2014.

AVELAR, Lúcia; RANGEL, Patrícia. Como as mulheres se representam na política? Os casos de Argentina e Brasil. In: BLAY, Eva Alterman; AVELAR, Lúcia (Orgs.). $\mathbf{5 0}$ anos de feminismo: Argentina, Brasil e Chile. São Paulo: Edusp, 2017.

BANASZAK, Lee Ann. Inside and Outside the State: Movement Insider Status, Tactics, and Public Policy Achievements. In: MEYER, David S.; JENNESS, Valerie; INGRAM, Helen M. (Orgs.). Routing the opposition: social movements, public policy, and democracy. Minneapolis: University of Minnesota Press, 2005.

BIROLI, Flávia. Feminismos, padrões de atuação e disputas políticas no Brasil contemporâneo. In: VEIGA, Ana Maria et al. (Orgs.). Mundo de Mulheres no Brasil. Curitiba: Editora CRV, 2019. p. 109-118.

BLAY, Eva Alterman; AVELAR, Lúcia (Orgs.). 50 anos de feminismo: Argentina, Brasil e Chile. São Paulo: Edusp, 2017.

BOHN, Simone. Feminismo estatal sob a presidência Lula: o caso da secretaria de políticas para as mulheres. Revista Debates. Porto Alegre: UFRGS, v. 4, n. 2, p. 81-106, 2010.

CARLOS, Euzeneia; DOWBOR, Monika; ALBUQUERQUE, Maria do Carmo Alves. Movimentos sociais e seus efeitos nas políticas públicas: balanço do debate e proposições analíticas. Civitas - Revista de Ciências Sociais. Porto Alegre: PUCRS, v. 17, n. 2, p. 360, 2017.

CAYRES, Domitila Costa. Ativismo Institucional no coração da Secretaria-Geral da Presidência da República: A Secretaria Nacional de Articulação Social no Governo Dilma Rousseff (2011-2014). (Tese) Programa de Pós-Graduação em Sociologia Política. Universidade Federal de Santa Catarina, Florianópolis - SC, 2015. 
FELTRAN, Gabriel. Deslocamentos - trajetórias individuais, relações entre sociedade civil e Estado no Brasil. In: DAGNINO, Evelina; OLVERA, Alberto; PANFICHI, Aldo (Orgs.). A disputa pela construção democrática na América Latina. Rio de Janeiro: Paz e Terra, 2006. p. 371-416.

GOMIDE, Alexandre de Ávila; PEREIRA, Ana Karine; MACHADO, Raphael Amorim. Burocracia e capacidade estatal na pesquisa brasileira. In: PIRES, R., LOTTA, G., OLIVEIRA, V. E. (Orgs.). Burocracia e políticas públicas no Brasil: interseções analíticas. Brasília: Instituto de Pesquisa Econômica Aplicada (Ipea), 2018. p. 87-104.

GONZALEZ, Débora de Fina. Os Mecanismos Institucionais de políticas para as Mulheres na América Latina: Arenas de/em disputas. Anais do Congreso de la Asociación de Estudios Latinoamericanos (LASA). Anais... Barcelona. 2018.

LAVALLE, Adrian Gurza et al. Movimentos sociais, institucionalização e domínios de agência. Centro de Estudos da Metrópole. São Paulo: CEM., p. 42, 2017.

MACHADO, Lia Zanotta. Feminismos brasileiros nas relações com o Estado. Contextos e incertezas. Cadernos Pagu. Campinas: UNICAMP, n. 47, 2016. Disponível em: <http://www.scielo.br/scielo.php?script=sci_arttext\&pid=S0104-83332016000200301\&lng=pt\&tlng=pt>. Acesso em: 22 abr. 2018.

PINTO, Céli Regina Jardim. Uma história do feminismo no Brasil. São Paulo: Editora Fundação Perseu Abramo, 2003.

RANGEL, Patrícia. Feminismo de Estado e Direitos Políticos das Mulheres: Argentina e Brasil. Anais do Seminário Internacional Fazendo Gênero, 10. Anais... Florianópolis. 2013.

SANTOS, Yumi Garcia Dos. A implementação dos órgãos governamentais de gênero no Brasil e o papel do movimento feminista: o caso do Conselho Estadual da Condição Feminina de São Paulo. Cadernos Pagu. Campinas: UNICAMP, n. 27, p. 401-426, 2006.

SCHUMAHER, Schuma. Os movimentos feministas ontem em hoje no Brasil: desafios da sua institucionalização. In: MATOS, Marlise; ALVAREZ, Sonia E. (Orgs.). Quem são as mulheres das políticas para as mulheres no Brasil: Expressões Feministas nas Conferências Nacionais de Políticas para as Mulheres. 1. ed. Porto Alegre - RS: Zouk, 2018. v. 2.

TARROW, Sidney. O poder em movimento: movimentos sociais e confronto político. Petrópolis: Vozes, 2009.

O presente trabalho foi realizado com apoio da Coordenação de Aperfeiçoamento de Pessoal de Nivel Superior - Brasil (CAPES) - Código de Financiamento 001. 